\title{
Self medication pattern in rural areas in Pune, India
}

\author{
Yogendra Keche, Radha Yegnanarayan, Shraddha Bhoyar, Rashi Agrawal, Roshani Chavan \\ and Priyanka Mahendrakar
}

Department of Pharmacology, Smt Kashibai Navale Medical College and Hospital, Narhe Abmegaon, Pune, Maharashtra, India-411041

Submission Date: 27-5-2012; Accepted Date: 26-6-2012

A B STRACT

Objective: This study was carried to analyze the self medication pattern in rural areas of Pune. Method: Semi-structured questionnaire was used for collection of data. Information about age, sex, name of the self medication, diagnosis for the use of self medication, source of information about the self medication and adverse effects reported to self medications was collected. Results: NSAIDs (33.33), antibiotics (10.32), vitamins (14.08) and GIT ailment drugs (13.61) are most commonly used as self medication in rural areas. Other drugs that self medicated are: drugs for upper respiratory tract infection, antibiotics, antihypertensives, anticonvulsants and diuretics. Information about the self medication was predominantly obtained from previous prescription of doctors (64.32\%) and from chemists (23\%). Antibiotics like macrolides, fluoroquinolones, cephalosporins, antihelminthics, and furazolidine were taken as self medication in rural areas. $50 \%$ of antibiotics used as self medication was associated with development of ADRs. The adverse effects reported with antibiotics self medication were: vomiting, hyperacidity, gastrointestinal discomfort. $21.13 \%$ of persons reported adverse effects with NSAIDs self medication. Adverse effects reported with analgesic use in this study were: hyperacidity, skin rashes, nausea. Conclusions: NSAIDs, antibiotics, vitamins and GIT ailment drugs are commonly self medicated in rural areas of Pune. The self medication of antibiotics is disturbing, as these are liable for drug resistance and severe ADRs and hence should be taken under supervision only. Pharmacists, key person in rural areas, can provide information about adverse effects of self medicated drugs and also can guide about proper precautions to be taken for self medication.

Keywords: ADRs to self medication, Antibiotic self medication, NSAIDs self medication

\section{INTRODUCTION}

Self medication or non prescription drug use is common in developing countries. ${ }^{1,2}$ Self-medication can be defined as obtaining and consuming drugs without the advice of a physician either for diagnosis, prescription or surveillance of treatment. ${ }^{3}$ The patients diagnose their own illness and buy a specific drug from medical shops to treat it. Person self medicate themselves by taking more or less than the recommended dose/frequency of drug administration and duration of therapy of drugs. It has been observed that people use either prescription or non prescription drugs for self

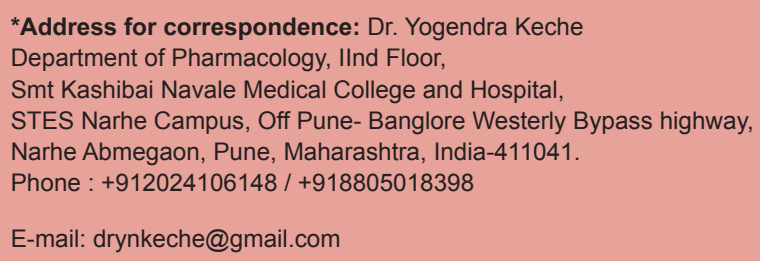

E-mail: drynkeche@gmail.com

DOI: $10.5530 /$ ijmedph.2.4.2 medication. Taking self medication without doctors supervision can be dangerous as it may lead to dangerous drug interactions and adverse effects. Studies on self-medication patterns and the prevalence of non-doctor prescribing in India are lacking. In one study, it was reported that there was increase in reporting of ADRs to self medication. ${ }^{2}$ Increasing cost of treatment and poor socio-economic status in rural areas may increase use of self medication. ${ }^{1,2}$ Various previous studies concluded that self medication NSAIDs being predominantly common. ${ }^{1,2,4}$ Hence, we undertook this study, to explore self medication pattern of other drugs including NSAIDs in rural areas of Pune, Maharashtra, India with following aims and objectives:

\section{AIMS AND OBJECTIVES OF THE STUDY:}

1. To find out common self medications used in rural areas of Pune

2. To find out the common self medications which cause ADRs 
3. To know the common symptoms/signs/diagnosis for self medication use in rural areas of Pune

4. To find out association of demographic factors for self medication use in rural areas of Pune

\section{MATERIALS AND METHODS}

STUDY SITE: The data for this study was collected by II MBBS students of Smt. Kashibai Navale Medical College and Hospital, Narhe Ambegaon, Pune, Maharashtra, India by surveying the population who were taking self medication from medical shops located in rural areas of Pune.

STUDY DESIGN AND SAMPLING: It was a cross sectional observational study. The data was collected from June 2010-February 2011. Pune is one of main Information Technology hubs and industrial cities in India. Much of the industrial population live in rural areas of Pune which is also developing and cost of living in rural areas is less as compared to urban area. II MBBS students carried out survey in medical shops located in rural areas of Pune. The students had been given an option to collect data from medical shops near their residence if they resided in rural areas or from medical shops located in Narhe/Dhayari rural areas.

\section{STUDY TOOLS}

DATA COLLECTION: II MBBS students of Smt Kashibai Navale Medical college and Hospital collected data from Narhe and Dhayari rural areas of lower socio-economic status. Semi-structured questionnaire prepared by Department of Pharmacology was used for data collection.

INFORMATION OBTAINED: 1) Name of self medication, duration, dose, frequency of drug administration. 2) Symptoms for which drugs were used. 3) Source of information for self medication: doctor, chemist, neighbor, advertisement on TV/ Newspaper. 4) Adverse effects to self medication seen in patients.

Rationality of fixed dose combinations (FDCs) self medication was assessed according to WHO Model List of Essential Drugs, $17^{\text {th }}$ Edition. ${ }^{5}$

\section{STATISTICAL ANALYSIS}

As there is absence of substantial data for self medication in rural areas, we had taken approximately 250 self medications as sample size, out of which, for 213 self medications, we had complete information. Hence we carry out analysis of 213 self medications. Data was expressed as number or percentages of persons taking self medication. Proportion of persons for different self medications was found out and comparison was done between the different drug groups of self medication.

\section{RESULTS}

SOCIO-DEMOGRAPHIC CHARACTERISTICS OF STUDY POPULATION: There was no significant difference in male and female distribution in this study (Table 1).

$50 \%$ self medication in this study was of FDCs and out of these FDCs only 28\% were rational FDCs according to WHO Model List for Essential Drug $2011^{5}$ (Table 1).

DRUG GROUPS FOR SELF MEDICATION USE AND ADVERSE EFFECTS REPORTED TO SELF MEDICATION: Analgesics, vitamins, GIT ailment drugs and antibiotics form the major bulk of self medication (Table 2).

\begin{tabular}{lc}
\multicolumn{2}{l}{ Table 1: Demographic characteristics of self medication } \\
\hline S.No. & No. / $(\%)$ \\
\hline Total self medications & 213 \\
Sex : Male & $113(53.05)$ \\
$\quad$ Female & $100(46.95)$ \\
Drugs used for self medication & \\
Single drug & $110(51.64)$ \\
Fixed dose combinations & $103(48.36)$ \\
Rational combinations & $29(28.15)$ \\
Income Groups & \\
$<\mathbf{1 0 0 0 0}$ & $97(45.54)$ \\
$\mathbf{1 0 0 0 0 - 2 5 0 0 0}$ & $81(78.64)$ \\
$\mathbf{2 5 0 0 0 - 5 0 0 0 0}$ & $16(7.51)$ \\
$\mathbf{5 0 0 0 0 0}$ & $2(0.93)$ \\
\hline
\end{tabular}

\begin{tabular}{lcc}
\multicolumn{3}{l}{ Table 2: Self medication drug groups with ADRs } \\
\hline $\begin{array}{l}\text { Name of the drug } \\
\text { Group }\end{array}$ & $\begin{array}{c}\text { No./ (\%) of self } \\
\text { medications }\end{array}$ & $\begin{array}{c}\text { No./ (\%) of ADRs } \\
\text { reported }\end{array}$ \\
\hline RS & $15(7.04)$ & $6(40)$ \\
Analgesics & $71(33.33)$ & $15(21.13)$ \\
CVS, CNS, Diabetes & $24(11.26)$ & $2(8.33)$ \\
Vitamins, Minerals & $30(14.08)$ & $2(6.66)$ \\
Antibiotics & $22(10.32)$ & $11(50)$ \\
GIT ailment drugs & $29(13.61)$ & 0 \\
Herbal drugs & $1(0.46)$ & 0 \\
Skin & 0 & 0 \\
Others & $21(9.86)$ & $5(23.81)$ \\
Total & 213 & 41 \\
\hline
\end{tabular}


More number of ADRs to analgesics and antibiotics were reported by the study population. $50 \%$ of antibiotic self medication use in this study was associated with development of ADRs (Table 2).

SOURCE OF INFORMATION FOR SELF MEDICATION: Commonest source for information of self medication in rural areas was initial doctor's prescription (64.32) and chemist, neighbor and advertisement were other sources of self medication (Table 3 ).

\section{SYMPTOMS/SIGNS OR DIAGNOSIS FOR SELF MEDICATION}

USE: Pain symptoms/signs, different GIT ailments, prophylactic therapies for pregnancy, anemia and arthritis were the common diagnose for which the self medication was used (Table 4).

\section{ADVERSE EFFECTS TO SELF MEDICATIONS AND NATURE OF} ADVERSE EFFECTS: Total 41 ADRs were reported in this study and self medication causing drugs were taken for 117 times in this study. Among the ADRs, least number of ADRs (6.66) were reported to paracetamol, whereas $75 \%$ ADRs to ciprofloxacin self medication had been reported (Table 5).

\begin{tabular}{lc}
\hline Table 3: Sources of information for self medication \\
\hline Sources of drug information & No./ (\%) \\
\hline Initial doctor's prescription & $137(64.32)$ \\
Chemist & $49(23)$ \\
Neighbor & $12(5.63)$ \\
Advertisement & $15(7.04)$ \\
\hline
\end{tabular}

\begin{tabular}{|c|c|}
\hline $\begin{array}{l}\text { Diagnosis for self } \\
\text { medication use }\end{array}$ & $\begin{array}{l}\text { No. of times/ } \\
(\%) \text { of self } \\
\text { medications }\end{array}$ \\
\hline $\begin{array}{l}\text { Pain symptoms/signs: Fever, myalgia, } \\
\text { swelling, fracture pain, pain in abdomen, } \\
\text { joint pain, neck pain, headache, } \\
\text { dysmenorrhoea, osteoarthritis }\end{array}$ & $71(33.33)$ \\
\hline \multicolumn{2}{|l|}{ GIT ailment } \\
\hline Diarrhea & $14(6.57)$ \\
\hline Hyperacidity & $15(7.04)$ \\
\hline Epilepsy & $4(1.88)$ \\
\hline $\begin{array}{l}\text { Infections: wound infection, ear infection, } \\
\text { cellulites, urinary tract infection }\end{array}$ & $13(6.10)$ \\
\hline Fungal infection & $9(4.22)$ \\
\hline \multicolumn{2}{|l|}{ Tinea cruris, tinea corporis } \\
\hline RS & $15(7.04)$ \\
\hline \multicolumn{2}{|l|}{$\begin{array}{l}\text { Common cold, throat pain, allergic rhinitis, } \\
\text { cough }\end{array}$} \\
\hline Diabetes & $9(4.22)$ \\
\hline Hypertension & $8(3.76)$ \\
\hline Insomnia & $2(0.93)$ \\
\hline Anxiety & $1(0.46)$ \\
\hline $\begin{array}{l}\text { Prophylactic use } \\
\text { Pregnancy, Osteoarthritis, Anemia }\end{array}$ & $30(14.08)$ \\
\hline \multicolumn{2}{|l|}{ Other } \\
\hline TB & $3(1.41)$ \\
\hline Urinary incontinence & $2(0.93)$ \\
\hline Vertebral compression & $1(0.46)$ \\
\hline Osteoarthritis & $7(3.28)$ \\
\hline Hepatomegaly & $1(0.46)$ \\
\hline Skin allergy & $1(0.46)$ \\
\hline Leprosy & $1(0.46)$ \\
\hline Sunburn dermatitis & $1(0.46)$ \\
\hline Eye problem-redness, watering & $5(2.34)$ \\
\hline
\end{tabular}

\begin{tabular}{|c|c|c|c|c|}
\hline Drug group & Name of drug & ADR reported & No. of ADRs & No. of self medication \\
\hline \multirow[t]{8}{*}{ Analgesics } & Mefenamic acid + Dicyclomine & Hyperacidity & 3 & 14 \\
\hline & Paracetamol & Hyperacidity & 1 & 15 \\
\hline & Aceclofenac & Hyperacidity & 1 & 2 \\
\hline & Diclofenac + Chymotrypsin + trypsin & Hyperacidity & 1 & 3 \\
\hline & Diclofenac + Paracetamol & Nausea, Hyperacidity, skin rash & 5 & 9 \\
\hline & Diclofenac gel & Burning sensation over skin & 2 & 5 \\
\hline & Diclofenac + seratiopeptidase & Hyperacidity & 1 & 1 \\
\hline & Diclofenac & Hyperacidity & 1 & 3 \\
\hline \multirow{6}{*}{$\begin{array}{l}\text { Antibiotics/ } \\
\text { Chemotherapeutic } \\
\text { agents }\end{array}$} & INH + Rifampcin & Weakness & 2 & 3 \\
\hline & Metronidazole & Hyperacidity & 2 & 2 \\
\hline & Fluconazole & Hyperacidity & 1 & 9 \\
\hline & Amoxycillin + clavulenic acid & Pain in abdomen Diarrhoea & 2 & 5 \\
\hline & Ciprofloxacin & Hyperacidity & 3 & 4 \\
\hline & Cefuroxime & Hyperacidity, vomiting & 1 & 1 \\
\hline Nutrients & Calcium + vitamin D & constipation & 2 & 10 \\
\hline RS & Cough syrup & sedation & 6 & 7 \\
\hline Antiepileptics & Phenytoin sodium & headache & 2 & 4 \\
\hline \multirow[t]{3}{*}{ Others } & Diacerin & Hyperacidity & 4 & 7 \\
\hline & Eye drops & Local burning & 1 & 3 \\
\hline & & Total & 41 & 117 \\
\hline
\end{tabular}




\section{DISCUSSION}

There is no sex difference observed for self medication use in this study. Most of the times, the self medications was used for adults. About $50 \%$ of self medication was observed in lower socio-economic status (monthly income less than Rs.10000/-). In developing countries like India, the poor socio-economic status, high cost of modern medicine and non availability of doctors in rural areas create problem for access for the healthcare services and may lead to increased self medication use. ${ }^{1}$ Self medication avoids some of the expenditure on health problems in rural areas.

$50 \%$ of self medications in this study were fixed dose combinations (FDCs) and only $28 \%$ of these were rational according WHO Model List for Essential Drugs, March 2011. ${ }^{5}$ FDCs self medication were taken largely from initial doctor's prescriptions, indicating availability of various irrational FDCs in drug stores in India. CIMS $^{6}$ and DRUG $\mathrm{TODAY}^{7}$ indices of marketed drugs have listed various irrational FDC preparations in the class of analgesics, antibiotics, vitamins and minerals, GIT ailment drugs and respiratory tract drugs are available in the Indian market. ${ }^{6,7}$

Among the different self medications observed in this study, analgesics have been most commonly used as self medication. Similar findings were observed in previous studies too. ${ }^{1,8}$ Vitamins, antibiotics and GIT ailment drugs are the other drugs that are also commonly self medicated.

Pain is commonly associated with analgesic self medication use. ADRs to analgesics self medication were also less severe in this study and that may be the reason for common self medication of analgesics. Paracetamol was found safest self medication as only one respondent reported ADR with paracetamol self medication. Analgesic fixed dose combinations counts for $60 \%$ ADRs that were reported with analgesics self medication. All analgesics FDCs that were self medicated in this study were irrational according to WHO Model List for Essential Drugs. ${ }^{5}$

Antimicrobials are commonly self medicated in rural areas. In this study, $10.32 \%$ antibiotics were self medicated and 50\% antibiotics self medication were associated with ADRs. It was also seen that self medication of antibiotics was taken for less duration of time (average time in this study was less than 3 days) and in inappropriate doses. It was noted previously that self medication of antibiotics is associated with high resistance level. ${ }^{9}$ We can curb self medication practice of antibiotics if it is given only on advice of prescriber, trained pharmacists and also by educating general population about self medication of antibiotics and making them aware about antibiotic resistance. $^{9}$

Vitamins/minerals fixed dose combination easily available for self medication, should not be taken unnecessarily. Self medication of vitamins/minerals only add to the expenditure bill of the patient without giving any potential benefit. ${ }^{10}$ Misconception in the community about power booster property of vitamins need to be removed. Regulation of advertisement are needed for preventing unnecessary use of vitamins/minerals as self medication. WHO Model List for Essential Drugs includes ascorbic acid, calcium, ferrous salts, folic acid, nicotinamide, pyridoxine, retinol, riboflavin, and thiamine like vitamins and minerals. The only fixed dose combination that has got place WHO Essential Medicine list in vitamin/mineral category is of ferrous salt and folic acid. ${ }^{5}$

Antacids were commonly taken as self medication in this study. Mehuys et al. (2009) ${ }^{11}$ observed that $95.1 \%$ persons got the symptom relief of gastrointestinal symptoms who were taking self medications for GIT ailments. This may be the reason for increase self medication use for treatment of gastrointestinal symptoms.

Cough syrups, antihistaminics, decongestants were used as self medication by $7.04 \%$ study population. Antihypertensive, antidiabetic, antithyroid drugs were also used as self medication in this study. Similar type of self medication pattern was observed in a previous study. ${ }^{12}$ All these drug groups has potential for causing dangerous ADRs, hence these drugs should be used cautiously for self medication.

Pharmacists can play key role by providing the patients information of warning symptoms needing urgent medical aids and about the adverse effects. ${ }^{10,11}$

Previous doctor's prescription (64.32\%) was the major source of self medications information in this study, followed by chemists adivce ( $23 \%$ ). Doctor's prescriptions, chemists, neighbor and advertisements are the common source of information as observed in previous studies. ${ }^{1,2,13}$ Doctors are not available in time in rural areas ${ }^{1}$, this might have tempted the rural population to use initial doctor's prescription for self medication.

The factors that influence self-medication are patient satisfaction with the healthcare provider, cost of the drugs, educational level, socioeconomic factors, age and gender. ${ }^{4}$ In this study, non availability of healthcare provider, low 
socio-economic status, decreased healthcare cost, younger age were the factors observed that can affect self medication use. Interactions between prescribed drugs and the drugs taken for self-medication is an important risk factor of which healthcare providers must be aware of. ${ }^{3,4}$ We had not evaluated educational levels of study population in this study and this is the limitation of our study.

\section{CONCLUSIONS}

Easy availability of drugs from pharmacist, decreased cost of therapy by using self medication are major factors for increased use of self medication. Most of the drugs used for self medication are liable to cause ADRs. Previous prescription of doctors, pharmacist, neighbor and advertisement were the common sources of information of drugs for self medication. NSAIDs and GIT drugs are commonly self medicated in rural areas irrespective of socio-economic status. As analgesic combination leads to more number of ADRs, they should be taken with doctors advice. The self medication of antibiotics is disturbing, as these are liable for drug resistance and severe ADRs and hence should be taken under supervision only. Pharmacists, a key person in rural areas, can provide information about adverse effects of self medicated drugs and can also guide about proper self medication of drugs.

\section{REFERENCES}

1. Shankar RR, Partha $P$, Shenoy $N$. Self medication and non-doctor prescription practices in Pokhara valley, Western Nepal: a questionnairebased study. BMC Fam Pract 2002; 3:17.

2. Sharma R, Verma U, Sharma CL, Kapoor B. Self medication among urban population of Jammu City. Ind J Pharmacol 2005; 37(1): 37-45.

3. Montastruc JL, Bagheri H, Geraud T, Lapeyre MM. Pharmacovigilance of self medication. Therapie 1997; 52(2): 105-10.

4. Habeeb GE, Gearhart JG. Common patient symptoms: patterns of self treatment and prevention. J Miss State Med Assoc 1993; 34(6): 179-81.

5. Essential Medicines WHO Model List (Adults), $17^{\text {th }}$ edition, March 2011.

6. CIMS, July-Oct 2011 (update 3).

7. DRUG TODAY, July-Sept 2011 (volume 1 \& 2).

8. Keche Y, Patil D. Self Medication Use in Nagpur City, Central India. Inventi Impact: Pharmacy Practice 2010; 1(1): 22-4.

9. Grigoryan L, Haaijer-Ruskamp FM, Burgerhof JGM, Mechtler R, Deschepper R, Tambic-Adrasevic A, et al. Self medication with Antimicrobial Drugs in Europe. Emerging Infectious Diseases 2006; 12(3):452-9.

10. Greenhalgh T. Drug prescription and self-medication in India: An exploratory survey. Social Science and Medicine 1987; 25(3):307-18.

11. Mehuys ELs, Bortel LV, Bolle LD, Tongrlen IV, Remon JP, Loos DD. SelfMedication of Upper Gastointestinal Symptoms: A community Pharmacy Study. The Annals of pharmacotherapy 2009; 43(5): 890-8.

12. Balbuena FR, Aranda AB, Figueras A. Self medication in older urban Mexicans: an observational, descriptive, cross sectional study. Drugs Aging 2009; 26(1): 51-60. 